\title{
Dental Health Management Methods for Children with Special Needs
}

\author{
Dyah Nawang Palupi Pratamawari \\ Department of Dental Public Health \\ Faculty of Dentistry, Universitas Brawijaya \\ Malang, Indonesia \\ dyah.nawang@gmail.com \\ Rachel Petrinathea Alfadiandra \\ Student \\ Faculty of Dentistry, Universitas Brawijaya \\ Malang, Indonesia \\ alfadiandrachel@gmail.com
}

\author{
Giza Romadhoni Rahmawati \\ Student \\ Faculty of Dentistry, Universitas Brawijaya \\ Malang, Indonesia \\ giza.rahmawati@yahoo.com \\ Rifdah Nisrinawati Maulina \\ Student \\ Faculty of Dentistry, Universitas Brawijaya \\ Malang, Indonesia \\ rifdah.nmaulina@gmail.com
}

\begin{abstract}
According to AAP (2008), children with special health care needs were defined as "children with any physical, developmental, mental, sensory, behavioral, cognitive, or emotional impairment or limiting condition that requires medical management, health care intervention, and/or specialized services or programs. The condition might be congenital, developmental, or acquired through disease, trauma, or environmental cause and may impose limitations in performing daily self-maintenance activities or substantial limitations in major life activities. Children with special needs had limitation in oral hygiene maintenance, therefore, were more vulnerable to caries and other periodontal disease. Dental treatment was not as easy as in normal children; therefore, special preventive dental management methods are needed. Objective: This review was prepared to present and to critically evaluate some preventive dental management methods that have been developed in the last decade. The literature review was done to determine some methods that could be used as a preventive dental management for special needs children. As many as 3 methods had been developed, and these methods were critically evaluated to determine their benefits and limitations. Conclusion: Good cooperation of government, caregiver, teacher and dentists is needed $\mathbf{t}$ provide preventive dental health methods for children with special needs to reduce the risk of caries and periodontal disease.
\end{abstract}

Keywords-children with special needs, preventive dental management, home dental prevention, audiovisual media

\section{INTRODUCTION}

According to American Academy of Pediatric Dentistry (2008), special health care needs were defined as "any physical, developmental, mental, sensory, behavioral, cognitive, or emotional impairment or limiting condition that requires medical management, health care intervention, and/or use of specialized services or programs [1]. The condition may be congenital, developmental, or acquired through disease, trauma, or environmental cause and may impose limitations in performing daily self-maintenance activities or substantial limitations in major life activities [1]. Health care for individuals with special needs requires a specialized knowledge acquired by additional training, as well as increased awareness and attention, adaptation, and accommodative measures beyond what are considered routine [2]. Special needs children may have great limitations in oral hygiene performance due to their potential motor, sensory, and intellectual disabilities, insufficient or sometimes complete dysfunction of stomatognathic apparatus; therefore, were more vulnerable with caries and other periodontal disease [1]. Dental treatment was not as easy as in normal children; therefore, preventive dental management with several methods can be done. The purpose of this literature review are to show some preventive dental management methods that can maintain the oral health of special needs children [1].

\section{MATERIAL AND METHODS}

This is a literature review by nationally and internationally searching some relevant using ScienceDirect, AAP News \& Journal Gateway and Elsevier database. First, 20.607 articles from 2008 until 2017 were found with keyword of "preventive treatment for special needs children", "home care dental preventive" and "audiovisual media for special needs children". There were only 55 articles out of 20.607 articles that were relevant with our review. These 55 articles were evaluated. It was found that 15 articles fulfilled the criteria; 8 articles had high quality, 5 articles had medium quality and 2 articles had low quality.

\section{RESULTS AND DISCUSSION}

The first method of dental health management for children with special needs found and analyzed from these articles was Dental Home or Oral Home care [1]. According to American Association of Pediatric Dental (AAPD) Dental Home concept was defined as the ongoing relationship between the dentist and the patient, inclusive of all aspects of oral health care 
delivered in a comprehensive, continuously accessible, coordinated, and family-centered way [1]. The Dental home concept should provide: comprehensive oral health care, including acute care and preventive services in accordance with AAPD periodicity schedules; comprehensive assessment for oral diseases and conditions; individualized preventive dental health program based on a caries-risk assessment and a periodontal disease risk assessment; anticipatory guidance about growth and development issues (teething, digit or pacifier habits); plan for acute dental trauma; information about proper care of the child's teeth and gingivae, this would include the prevention, diagnosis, and treatment of disease of the supporting and surrounding tissues and the maintenance of health, function, and esthetics of those structures and tissues; dietary counseling; referrals to dental specialists when care cannot directly be provided within the dental home; education regarding future referral to a dentist knowledgeable and comfortable with adult oral health issues for continuing oral health care; referral at an age determined by patient, parent, and pediatric dentist. Some research had been conducted on this method and had proven it to successfully increase the dental health in children with special needs [1]. The research conducted by Agnintia D et al. on visually impaired children showed a significant influence of home care technique to the oral hygiene of visually impaired students in SDLB A - YKAB Surakarta with $\mathrm{p}$ value $=0,00(p<0,05)$ [2]. Another research by Mackichan MD et al. also showed the importance of parents' involvement in the individual program planning process and its necessity to involve them at the beginning of individual program development process [3]. By creating a warm and welcoming atmosphere, educators could truly connect with parents from the beginning of the process [3]. Educators and parents could then become partners in the student's learning [3]. When, and only when, a genuine partnership exists between parents and educators, the Individual Program Plan could become much more than a form filling exercise [3]. Homer CJ et al. also concluded that medical homes concept improved health-related outcomes for children with special health care needs [4]. Thompson CL et al. concluded that First Dental Home (FDH) visit had a positive impact on Texas parents by increasing the healthcare knowledge and practices [5]. This method was very effective [5]. However, this home care method had some limitations. According to Wiener RC et al. unmet needs for preventive dental care were associated with employment and financial burdens of the caregivers of special needs children [6]. Potential explanations for why some caregivers do not perceive a need for preventive dental care may involve differences in handling the complexity of the child's medical problems which overshadows concerns for preventive dental care, including problems such as a child's dysphagia, and gastroesophageal reflux [7]. Wiener RC et al. also showed that financial burden for access of all needed preventive dental care was higher than access of incomplete preventive dental care $(\mathrm{AOR}=1.54$ and 1.38 , respectively), while employment burden played a modest role (AOR $=1.01$ and 1.45 , respectively) [6].

Second method commonly used to improve the oral health care of children with special needs was using audiovisual media to promote the oral health. Some studies showed that this method was also successful [8]. Sandeep V et al. analyzed this method on students with hearing impairment, and the result showed that there was a decrease of plaque index average and gingival score significantly in study group, but only the decrease of plaque marginal and gingival score that observed in control group, and it was concluded that visual instruction like leaflet can be used as an effective dental education tools in CHI [8]. Chowdary PB et al. found that using verbal, braille text and tactile oral hygiene awareness instructions of oral hygiene can reduce the plaque scores and proved that this method was effective [9]. The audio visual method has the added advantage of repetitive usage with no additional cost which can be effectively used in developing countries [8]. This method is essential, but will not solve the problem alone. One study by Chachra $S$ et al. found contradictory results to the current study that direct communication through dentist proved to be the most effective communication approach compared to indirect communication by schoolteachers and through members of social organizations for oral health promotion [10]. Where special children are concerned, educational and motivational process should be extended to their parents, caregivers and instructors [9].

Another method that can be used to increase the oral health care for children with special needs was using integrated dental health system and increasing the awareness of the parents to bring the special needs children to the dentist when they reach 1-year-old [11]. The ideal integrated dental health system according to Paul M (2010) was one that is accessible, affordable, and staffed by educated and prepared providers and staff. In addition to these broad goals, short-term steps can be taken : alteration of accrediting standards of the Commission on Dental accreditation to require meaningful pre doctoral education in the area of care of the disabled; continuation or expansion of programs which have already increased the number of pediatric dentist training positions significantly in the last five years; amending dental practice acts to facilitate function of dental hygienists in care facilities to at least provide preventive services to special needs children; making dental case management an allowable Medicaid expense nationally; modifying national pediatric health supervision guidelines to place special needs children in dental offices by the time they reach one year of age; and mandating oral health as a consideration in guidelines for all special health care needs children, irrespective of the nature of the disability or need [11]. Norwood KW et al also recommended some steps to achieve this ideal integrated dental system, including learning to assess dental and periodontal health in children with special health care needs, recognizing risk 
factors that contribute to poor oral health with the use of the Oral Health Risk Assessment Tool, identifying dental professionals in the community who will provide a dental home for children with developmental disabilities (including providers for children who require sedation/ anesthesia), including anticipatory guidance on appropriate oral hygiene and habits for all children, especially those at high risk because of special health care needs or developmental disabilities, advocating oral care for children with developmental disabilities, developing collaborations with dental partners to coordinate care for children with developmental disabilities [12]. These ideal system, however, was still hard to achieve due to lack of dental education in parents with special needs and there was limited number of dental hygienist in some countries [13]. There are 28 countries with this method, such as Australia, Canada, Denmark, Finland, Ireland, Italy, Korea, Malta, Netherlands, Norway, Slovakia, South Africa, Sweden, United Kingdom, Austria, Czech Republic, Fiji, Germany, Israel, Japan, Latvia, Nepal, New Zealand, Portugal, Russia, Spain, Switzerland and USA [14].

The results of this review on some articles journals about dental health preventive for special needs children were done through 3 methods, i.e. with home care system where parents/caregiver are needed to take care of the children's oral hygiene, dental education that given by the teacher using audiovisual help, and an ideal oral health care system that is accessible, affordable, and staffed by educated and prepared providers and staff. It is important to provide the preventive dental health for special needs children with the good corporation from the government, caregiver, teacher and the dentist to reduce the risk of caries and periodontal disease in special needs children.

\section{REFERENCES}

[1] K.W. Norwood, R.L. Slayton, "Oral health care for children with developmental disabilities," American Academy of Pediatrics, vol. 131, pp. 614-619, March 2013.

[2] D. Agnintia, E. Karyadi, S.E. Yuletnawati, "Pengaruh home care terhadap kebersihan gigi dan mulut siswa tunanetra di SDLB A-YKAB Surakarta," Disertasi, Surakarta, Fakultas Kedokteran Gigi Universitas Muhammadiyah Surakarta, pp. 14, February 2014

[3] M.D. Mackichan, M.J. Harkins, "Inclusive education: perceptions of parents of children with special needs of the individual program planning process," Electronic Journal for Inclusive Education, vol. 3(1), pp. 1-28, March 2013.

[4] C.J. Homer, K. Klatka, D. Romm, K. Kuhlthau, S. Bloom, P. Newacheck, et al., "A review of the evidence for the medical home for children with specific special health care needs," Pediatrics, vol. 122(4), pp. 922-937, October 2008.

[5] C.L. Thompson, A.I. McCann, E.D. Schneiderman, "Does the Texas first dental home program improve parental oral care knowledge and practices," Pediatric Dentistry, vol. 39(2), pp. 124-129, March 2017.

[6] R.C. Wiener, R. Vohra, U. Sambamoorthi, S.S. Madhavan, "Caregiver burdens and preventive dental care for children with autism spectrum disorder, developmental disability and/or mental health conditions," National Survey of CSHCN 20092010, Maternal and Child Health Journal, vol. 20(12), pp. 2573 2580, Decmber 2016.

[7] P. Goel, M. Seghal, R. Mittal, "Evaluating the effectiveness of school-based dental health education program among students of different socioeconomic groups," Journal of Indian Society of Pedodontics and Preventive Dentistry, vol. 23(3), pp. 131-133, September 2005.

[8] V. Sandeep, C. Vinay, V. Madhuri, V.V. Rao, K.S. Uloopi, R.C. Sekhar, "Impact of visual instruction on oral hygiene status of children with hearing impairment," Journal of Indian Society of Pedodontics and Preventive Dentistry, vol. 32(1), pp. 39-43, February 2014

[9] P.B. Chowdary, K.S. Uloopi, C. Vinay, V.V. Rao, C. Rayala, "Impact of verbal, braille text, and tactile oral hygiene awareness instructions on oral health status of visually impaired children," Journal of Indian Society of Pedodontics and Preventive Dentistry, vol. 34(1), pp. 43-47, February 2016.

[10] S. Chachra, P. Dhawan, T. Kaur, A.K. Sharma, "The most effective and essential way of improving the oral health status education," Journal of Indian Society of Pedodontics and Preventive Dentistry, vol. 29(3), pp. 216-21, October 2011.

[11] S.C. Paul. Children with special health care needs; Patient, professional and systems issues. Pediatric Dentistry of Columbus Children's Hospital, The Ohio State University College of Dentistry.

[12] K.W. Norwood, R.L. Slayton, "Oral health care for children with developmental disabilities," Amerian Academy of Pediatrics, vol. 131, pp. 614-9, March 2013.

[13] M.H. Amitha, A.B. Aiswarya, M. Anshad, J. Anu, S Kanwardeep, V.C. Preethi, et al., "Special needs of special children-parental view," Nitte University Journal of Health Science, vol. 5, June 2015.

[14] International Federation of Dental Hygienists. (2017, August 28) Working Abroad as a Dental Hygienist. Available: <http://www.ifdh.org/work abroad.html >. 